\title{
El territorio habitado. Parkour, motricidades y afectos en la ciudad de Quito
}

\section{THE INHABITED TERRITORY. PARKOUR, MOTOR SKILLS, AND AFFECTIONS IN QUITO}

\author{
O TERRITÓRIO HABITADO. PARKOUR, HABILIDADES MOTORAS E AFETOS \\ NA CIDADE DE QUITO
}

Dennis-Javier Vásconez-Vaca ${ }^{1}$

Para citar este artículo: Vásconez-Vaca, D-J. (2019). El territorio habitado. Parkour, motricidades y afectos en la ciudad de Quito.

Perspectiva Geográfica, 24(2), 151-172. doi: 10.19053/01233769.8844

\section{Recepción:}

15 de noviembre de 2018

Evaluación:

8 de julio de 2019

Aprobación:

20 de agosto de 2019

\section{Resumen}

El presente artículo es una reflexión sobre movimiento corporal y afectividades en la ciudad de Quito, a través de una observación profunda y una larga reflexión sobre estos temas desde la óptica del parkour, práctica motriz dedicada a recorrer los espacios urbanos de la forma más fluida y eficaz posible por medio únicamente del cuerpo. A través de la experiencia de aprendizaje y práctica del parkour, entre las actividades del colectivo Étre Fort, este estudio indaga en las transformaciones que conlleva el ejercicio de esta disciplina sobre la ciudad, su producción espacial y su territorio habitado, a la vez que reflexiona sobre los elementos afectivos que surgen en dicha práctica y su papel en estas transformaciones.

Palabras clave: afectos, cuerpo, emociones, espacio urbano, habitar, movilidad, territorio. 


\section{Abstract}

This article is a reflection on body movement and affections in the city of Quito. These matters are deeply observed and carefully considered from the perspective of parkour, a motor activity in which practitioners move through urban spaces using their own bodies in the fastest and most effective way possible. Through the experience of learning and practicing parkour, among the activities of the Etre Fort collective, this study inquires into the transformations caused by this discipline in the city, its spatial production and inhabited territory, while pondering the affective elements arising from this practice and their role in such transformations.

Keywords: Affections, body, emotions, urban space, to inhabit, mobility, territory.

\section{Resumo}

O presente artigo é uma reflexão sobre o movimento corporal e as afetividades na cidade de Quito, através de uma observação profunda e uma longa reflexão sobre essas questões a partir da perspectiva do parkour, prática motora dedicada a percorrer os espaços urbanos da maneira mais fluida e eficaz possível somente por meio do corpo. Através da experiência de aprendizagem e prática do parkour, entre as atividades do coletivo Étre Fort, este estudo investiga nas transformações envolvidas no exercício dessa disciplina sobre a cidade, sua produção espacial e seu território habitado, refletindo ao mesmo tempo sobre os elementos afetivos que surgem em dita prática e seu papel nessas transformações.

Palavras chaves: afetos, corpo, emoções, espaço urbano, habitar, mobilidade, território. 


\section{Introducción}

El parkour, definido muchas veces como el arte del desplazamiento, es una práctica motriz que, en los últimos años, ha desarrollado cierta popularidad a través de películas y videos en redes sociales, los cuales destacan el sentido espectacular y las maniobras arriesgadas a lo largo de escenario urbano. Tanto en películas sobre esta temática como en diversas plataformas digitales, podemos ver osados practicantes que se desplazan por altos tejados y azoteas, como si de una millonaria producción de Hollywood se tratara.

Sin embargo, esta tendencia y la espectacularidad que la caracteriza no necesariamente representan las nociones centrales de esta práctica. El sentido clave del parkour, que materializa su nacimiento, yace en el juego y la exploración de la ciudad. Uno de los antecedentes más cercanos de esta disciplina se remonta al París del siglo XX, a finales de los años ochenta, en donde el bombero francés Raymond Belle desarrolla una práctica basada en el método natural, al cual modifica para llevarlo a la ciudad a través de la exploración (Leyden Rotawisky, 2015).

Creado a finales del siglo XIX por Georges Hébert, oficial de la marina francesa, el método natural es un sistema de entrenamiento militar que procura la recuperación de las habilidades del cuerpo y está basado en la experiencia de Hébert con diversas comunidades de vida más natural (Leyden Rotawisky, 2015). Casi un siglo después, Belle y su hijo David, junto con algunos amigos como Sebastián Foucaun, retoman este sistema y agregan una pequeña modificación al desarraigar cualquier noción de competencia del juego y la exploración de la urbe parisina (Leyden Rotawisky, 2015).
El componente más elemental del parkour es explorar en el espacio urbano nuevas formas de movimiento desde las habilidades del propio cuerpo. Esto, así como es medular en los conceptos de la práctica, es también una idea central en el colectivo Étre Fort, dedicado a la práctica y la enseñanza de esta disciplina en la ciudad de Quito. En este grupo, se hace del parkour una puerta de exploración hacia la ciudad, por medio de actividades como recorridos nocturnos semanales de dos horas y media de duración, entre otras iniciativas.

El presente artículo se basa un trabajo de observación etnográfica realizado entre enero y junio de 2018 a través de la participación en las actividades esta agrupación. En este proceso, se indaga en el papel que juega el movimiento corporal en la relación entre habitantes y espacio urbano, con especial énfasis en la influencia en las emociones y su papel en las formas de movimiento que median esta interacción, donde se utiliza el parkour como herramienta de impulso para profundizar en el espectro de movimiento corporal analizado.

\section{Habitar y movimiento,}

\section{aproximaciones teóricas}

La configuración del espacio urbano en las ciudades modernas tiene una clara influencia de las directrices productivas y económicas que caracterizan la actividad en estos entornos. En buena medida, esto se debe a que "las metrópolis siempre fueron la sede de la economía monetaria" (Simmel, 2002, p. 56). Sin embargo, en esa dinámica económica de la ciudad también influye un proceso de crecimiento exacerbado que tiene un evidente nexo con el desarrollo industrial y que Sennet 
(1997) ubica entre la mitad de los siglos XIX y $\mathrm{XX}$, lapso correspondiente a lo que llama la "revolución urbana" (p. 341).

Progresivamente, este avance del paradigma urbano moderno genera un clima de movimiento marcado por la rapidez, la eficiencia y la individualidad, en donde el sujeto se ve cada vez más aislado de su experiencia sensorial y, consecuentemente, mermado en su nivel de participación al momento de trasladarse a través de la urbe (Sennett, 1997). El movimiento en las ciudades ha adquirido una concepción marcada por estos ejes centrales orientados hacia lo productivo.

Este paradigma se conceptualiza recurrentemente como la movilidad urbana, una forma de movilización propia de las ciudades cuyo rasgo principal es la procura de un sistema eficiente y sostenible (Banco Mundial, 2002). La producción del espacio urbano frecuentemente procura favorecer una movilidad individualizada, acelerada y eficiente para los parámetros productivos de la ciudad. La planificación urbana busca "disminuir los tiempos de viaje" y "mejorar las conexiones al hacerlas más eficientes", mientras que el tiempo invertido por los habitantes en los medios de transporte masivos es "considerado como tiempo muerto" (Jirón e Iturra, 2011, p. 47).

Esto hace del espacio una herramienta tecnológica a nivel social y político, es decir, un apéndice de la estructura social que establece una configuración panóptica en la ciudad (De Certeau, 2007), destinada a vigilar y determinar las acciones permitidas para el sujeto, en este caso, las formas de movimiento legítimas en el espacio urbano. De este estructuración derivan una serie de libretos y guiones (Leyden Rotawisky, 2013) respecto de lo que el espacio permite o no hacer.
Sin embargo, el habitante encuentra modos, que proceden de su movimiento corporal, de expresar su subjetividad frente a este panorama. Así lo señala De Certeau (2007), quien plantea que el transeúnte de a pie produce la ciudad habitada mediante sus prácticas del andar, a través de las cuales el peatón halla formas de enunciarse a sí mismo por medio de su movimiento.

Estas prácticas del andar generan elementos como atajos, conexión de diversos puntos y varias otras formas en las que, a través de su movimiento, el peatón produce el espacio urbano desde su propia subjetividad (De Certeau, 2007). En este rumbo, el parkour implica un escenario en donde se extrapolan esas prácticas del andar hacia el extremo de sus posibilidades.

Trabajos como los de Scarnatto y Díaz, en La Plata, o el de Schargorodsky, en Avellaneda, demuestran que el parkour ha trascendido las fronteras de su origen parisino y se ha diversificado en numerosos contextos al rededor del mundo, como en el caso de Argentina. En este escenario, la práctica tiene que lidiar con las fronteras y estructuraciones espaciales propias de su medio local, y todas las tensiones que esto implica.

Scarnatto y Díaz (2010) destacan la forma en que los practicantes acumulan experiencias que se suman, en un aprendizaje que fomenta su autosuperación y se torna en "capital cultural hecho cuerpo" (Scarnatto \& Díaz, 2010, p. 10). En el caso de Avellaneda (Schargorodsky, 2015), se destacan los mecanismos que desarrollan los practicantes para desanclar estos códigos estrictamente entablados y generar sus propios hábitos o mecanismos de movilización que, a su vez, convergen con otros actores sociales en el mismo espacio, frente a los cuales pugnan por legitimar su práctica. 
Todas estas regulaciones y tensiones que se dan en disputa por el uso permitido revelan una tendencia en el espacio público de la urbe, que limita su apropiación desde la subjetividad. Hay formas claras y normalizadas de movilizarse por el espacio público, porque este no es reivindicable de forma permanente o susceptible de apropiación por parte del individuo (Goffman, 1979).

Los espacios públicos se configuran como escenarios de circulación donde las prácticas no permanecen y la ocupación no se prolonga indefinidamente, en una forma de espacialidad que Marc Augé (2001) denomina no lugar. Este no lugar, caracterizado por la transitoriedad de las prácticas en él desarrolladas, tiene sus raíces conceptuales en la perspectiva de Michel De Certeau (2007), para quien este espacio no localizado es producido a través del movimiento, y existe porque se practica y mientras se practica. Se hace por medio del andar, que se produce al transitarlo y que existe mientras se transita. Más que un lugar, un espacio que constituye fundamentalmente un hacer (Delgado, 1999).

En oposición, De Certeau plantea el territorio como un espacio que permanece, una zona delimitada que una comunidad ocupa de manera prolongada y a la que defiende de amenazas externas (Delgado, 1999). Un espacio en donde las prácticas permanecen y que, como territorio en donde se habita, es reivindicable como un bien susceptible de posesión a modo permanente (Goffman, 1979).

Esta noción de territorialidad tiende a dividir el espacio urbano en "unidades espaciales discretas, delimitadas" (Imilan Ojeda, Jirón Martínez \& Iturra Muñoz, 2015, p. 90) en las cuales se busca, desde la mirada antropológica, "rescatar o develar formas que se resisten a los procesos de indi- vidualización, anonimato e intercambio funcional tan celebrado en algún momento" (Imilan Ojeda et al., 2015, p. 90).

Esto deriva en una visión del habitante que se limita al territorio en donde reside o permanece prolongadamente, la unidad discreta de análisis espacial, como pudiera ser el barrio, ejemplo por excelencia del territorio cuyas inmediaciones definen las prácticas que configuran su identidad como sujeto habitante (Imilan Ojeda et al., 2015).

Sin embargo, la movilidad no solo es un medio accesorio para los fines productivos de la urbe, pues el territorio habitado se construye también a través de la movilidad. "Un aspecto que explica la importancia de la movilidad es la gran influencia que tiene en la vida cotidiana de las personas, puesto que sus vidas no se detienen al moverse" (Imilan Ojeda et al., 2015, p. 48). La movilidad abarca una infinidad de prácticas fundamentales en la vida del sujeto habitante. Por lo tanto, el territorio habitado se extiende hacia todas estas prácticas y formas de espacialidad que produce a través de la movilidad.

Para De Certeau (2007), la ciudad habitada se produce a través de las prácticas del andar, en donde el peatón se enuncia como individuo más allá de las "construcciones visuales, panópticas o teóricas" (De Certeau, 2007, p. 105) de la ciudad y halla formas de enunciarse a sí mismo a través de su movimiento corporal. Alicia Lindón (2009) describe este fenómeno más allá de la categoría de peatón, desde el concepto que denomina sujeto сиегро.

Este concepto plantea al habitante como un sujeto cuyo movimiento se hace desde el cuerpo en todo momento. Un sujeto que es corporal en general, no solo cuando su cuerpo es el principal medio mo- 
triz, sino en todas sus prácticas de movilidad. Este habitante corporal genera diversas formas de espacialidad al movilizarse por la ciudad, formas que son más transitorias, practicadas, que no delimitan un determinado espacio permanentemente, pero que se reproducen en el espacio urbano a través de la movilidad cotidiana.

Jirón e Iturra (2011) plantean, entre estas formas de espacialidad, los "lugares móviles" y los "lugares transientes". Los primeros se refieren a los espacios que se utilizan como medios de movilización, como buses, trenes y demás medios de transporte, y las formas de espacialidad que se elaboran en su uso cotidiano. Los segundos son lugares "de tránsito y transición" para el habitante, que se caracterizan como "espacios fijos a través de los cuales ocurre movilidad intensa, y son dotados de importancia por conveniencia, ocio, distracción, socialización y recreación" (Jirón \& Iturra, 2011, p. 47).

Tanto al interior de los medios de transporte como en los lugares de paso que se transita en la movilización cotidiana, el habitante desarrolla una larga serie de prácticas que le son de alguna forma productivas, y que espacializan ese lugar transitorio en donde se movilizan (Jirón e Iturra, 2011). Tanto leer, escuchar radio en un bus o aprovechar la actividad comercial de una estación de metro para interactuar son prácticas anexas a la movilidad, que espacializan y dotan de sentido estos lugares transitorios que se recorren de forma cotidiana ( $\mathrm{Ji}$ rón \& Iturra, 2011).

Todos estos lugares, tanto móviles como transientes, pasan a ser parte del territorio habitado en la ciudad. El espacio urbano, como territorio habitado, se pasa a comprender a partir de las prácticas de movilidad que lo producen, un espacio que "no es ni anterior ni posterior a las prácticas, sino parte de ellas mismas" (Imilan Ojeda et al., 2015).

Este espacio generado a partir de la movilidad y sus prácticas subyacentes ofrece un nueva perspectiva de ciudad habitada, una "ciudad movimiento" (Lindón, 2017) en donde la espacialidad no se limita a la localización del lugar en un punto fijo. Este espacio se vuelve corpóreo, "se hace cuerpo en el habitante, pero a la vez se transforma en una extensión de este" (Imilan Ojeda et al., 2015) a través de la interacción móvil con el espacio.

En otras palabras, el espacio se corporiza en las interacciones móviles, es un espacio corpóreo en donde los objetos, las estructuras y los demás elementos materiales allí presentes participan activamente de los procesos políticos y sociales que se sostienen sobre ese espacio (Lindón, 2009). Por lo tanto, en las prácticas de movilidad, el habitante establece interrelaciones corpóreas, no solo en, sino con el espacio urbano. El espacio se produce a través de "mediaciones sensibles con las que se comunican los sujetos y sus entornos", y se torna en un "espacio vivido, experimentado en el sentido más fenomenológico" (Imilan Ojeda et al., 2015, p. 92).

Este sentido fenomenológico hace referencia al amplio espectro de elementos perceptivos o sensitivos que atraviesan esa experiencia del espacio, que permiten al sujeto cuerpo conocer el espacio e interactuar con él. Todos estos elementos definen la dimensión del sujeto cuerpo, caracterizada por el ámbito sensible desde la acepción más amplia de este término, es decir, lo sensible como perceptivo así como a nivel emotivo. 
En este sentido, la relación corpórea que sostienen sujetos y espacios viene mediada por todas esas sensaciones que despierta la experiencia del espacio, las cuales incluyen no solo las percepciones, sino, además, las emociones. Estas últimas representan un elemento cada vez más atendido en el estudio del espacio. Para algunos autores, las emociones, de hecho, juegan un rol central en las relaciones espaciales tanto como en cualquier otra relación humana, pues "el mundo se vive y se constituye a través de las emociones" (Pile, 2009, p. 6).

Desde la geografía emocional que propone Steve Pile (2009), esas emociones son localizables en el cuerpo, en las relaciones entre cuerpos. Lindón (2009) plantea una noción similar, pues afirma que el sujeto cuerpo coexiste con el sujeto sentimiento, una dimensión que siempre está presente en la intencionalidad motriz del sujeto cuerpo y que se tiñe sobre los espacios en la medida en que el habitante los atraviesa.

Esto significa que las emociones tienen una incidencia clave en las formas en que se produce la ciudad movimiento. Las prácticas motrices están no solo teñidas de emociones, son guiadas por estas. Las emociones no solo producen una interpretación discursiva o representacional del espacio, sino que inciden sobre las distintas formas en que el habitante produce ese espacio al moverse por él $\mathrm{y}$, consecuentemente, sobre las posibilidades y capacidades de dicho habitante para practicar unos $u$ otros espacios de formas determinadas.

Lindón (2009) plantea dos escenarios emocionales básicos: la topofilia, ligada al apego por los espacios, y la topofobia, relacionada con el rechazo y la repulsión por ellos. Ambos implican una forma diferente de practicar un respectivo espacio según el sujeto sentimiento que allí se impregna. La experiencia de cada espacio concreto genera en el habitante sentimientos que influyen sobre la forma y la frecuencia en que se moviliza por allí.

Las emociones, por tanto, tienen relación directa con la acción. Una definición clara sobre el papel de las emociones en esta relación es la noción de afectos que plantea Leyden Rotawisky: se definen como modificaciones corporales que pasan por lo perceptivo a nivel sensible, que "no se distinguen entre emotivos y somáticos" (2015, p. 207), y que son capaces de potenciar, limitar o modificar de alguna forma la capacidad de acción del sujeto (Leyden Rotawisky, 2013).

En este caso, esa acción es fundamentalmente motriz, y las modificaciones proceden de esta interacción entre habitantes y espacio que se da a nivel corporal, esa experiencia del espacio que es el movimiento. De este modo, las emociones a indagar en este análisis pasan por la experiencia corporal del sujeto, entendida como este amplio espectro sensible que abarca lo emotivo y lo sensitivo, en donde "el cuerpo, lo somático, toma una nueva dimensión" (Imilan Ojeda et al., 2015), en la cual se pueden rastrear vestigios de esos afectos que produce el espacio en el habitante que lo experimenta.

Por otro lado, estos afectos no solo dejan sus huellas rastreables en el cuerpo, sino que atraviesan $\mathrm{y}$ transforman a quienes afectan hasta generar devenires (Leyden Rotawisky, 2013). En el caso del parkour y los afectos que lo rodean, Leyden Rotawisky (2013) define ese devenir como un proceso de contaminación en el cual practicantes y espacio se generan mutaciones hasta transformar sus identidades respectivas, lo cual nos lleva a la pregunta central a tratar en este artículo: cómo estos intercambios afectivos presentes en la práctica 
del parkour transforman el territorio urbano que se habita corporal y emocionalmente, comprendiendo ese territorio como un hacer, como ese que se hace al movilizarse de un punto a otro. De forma más sucinta, cómo transforman esos intercambios afectivos, presentes en el parkour, el territorio habitado a través de las prácticas motrices.

\section{Metodología}

Esta investigación fue realizada mediante una metodología cualitativa, que conjuga algunas técnicas de estudio en una triangulación de perspectivas: la observación del propio investigador, la recopilación y el análisis de datos desde los recursos de la antropología visual y, finalmente, los criterios de varios miembros del colectivo que participaron del proceso de campo.
Estas técnicas se aplican de forma consecuente con cada faceta del trabajo de campo al que corresponden. La primera de estas, desarrollada entre enero y abril de 2018, corresponde a una observación participante como aprendiz de la experiencia, con énfasis hacia la corporalidad que se desarrolla a través de la práctica, en lo que Leyden Rotawisky (2013) denomina el conocimiento incorporado subyacente en esta disciplina.

Esto implicó la participación continua en los talleres de parkour permanentes dictados por Étre Fort en el Parque Urbano Cumandá (Figura 1), ubicado en la avenida 24 de Mayo, a las faldas del Paneci1lo, cerro conocido como el vértice que separa el norte y el sur de la ciudad. El grupo denomina este espacio permanente del parque Escuela de Movimiento.

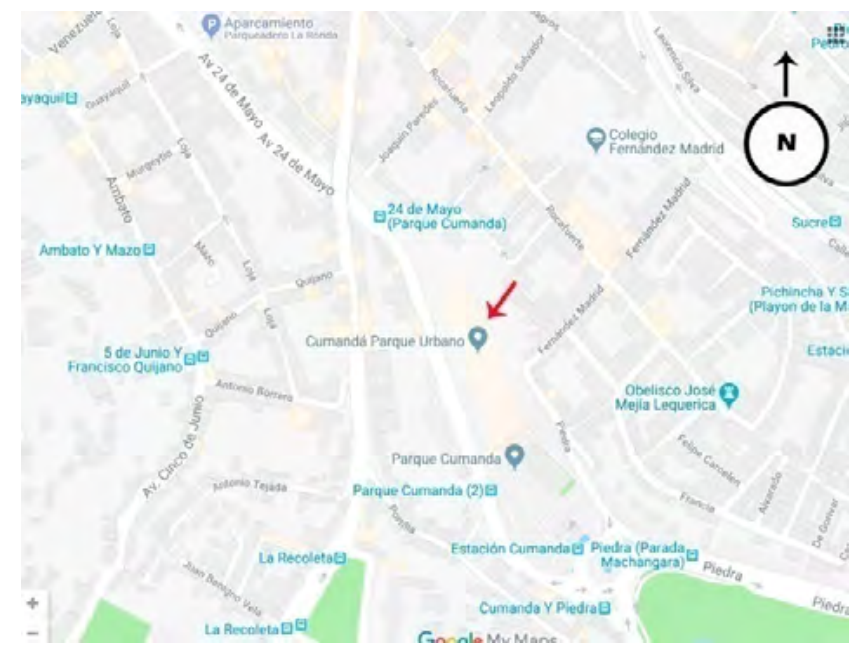

FIGURA 1.

Ubicación del Parque Urbano

Cumandá.

Fuente: Google My Maps.
Luego de la familiarización con los talleres, el proceso avanzó hacia la actividad del colectivo que más llamativa resulta para la investigación: los recorridos nocturnos. Estos tienen una duración aproximada de dos horas y media y abarcan distancias entre los cinco y los siete kilómetros. Son posteriores al taller, y se desarrollan en la noche para que los asistentes puedan culminar con sus actividades escolares o laborales y sumarse al recorrido.

Su característica fundamental, no obstante, es el uso de la ciudad, de sus espacios de uso cotidiano, para la práctica. Esto hace de los recorridos noc- 
turnos el principal escenario de observación, pues permiten apreciar los intercambios afectivos que genera el parkour en el territorio propiamente urbano, fuera de los lindes del espacio predispuesto para el aprendizaje.

En este rumbo, la segunda etapa de investigación, llevada a cabo entre abril y mayo de 2018 , se involucra en los recorridos nocturnos mediante el recurso de la filmación, ampliamente discutido desde la antropología visual. El video tiene aquí el propósito de ser una puerta hacia el cuerpo y el movimiento, a las relaciones entre cuerpos que se tejen entre practicantes y espacio por medio del movimiento, pues más allá de la mera recopilación de datos enunciados o verbalizados, este recurso tiene una extensa gama de posibilidades como un participante más del proceso de campo, con capacidad de acción y movimiento (MacDougall, 2006).

Bajo este rumbo, durante la investigación se registraron en video seis recorridos nocturnos, cada uno con sus datos particularmente relevantes y su importancia contextual en la realidad investigada, los cuales suman aproximadamente 38 kilómetros y se extienden hacia los cuatro puntos cardinales respecto al Parque Cumandá, punto de partida en casi todos los recorridos.

Los dos primeros se abren hacia el noroeste y noreste del parque respectivamente. En determinado punto, hacen un giro y regresan hacia el sur para terminar exactamente en el mismo punto, el parque del barrio Villaflora, detrás del Panecillo. La tercera y la cuarta ruta exploran el sector de San José de Monjas, asentado en una loma al noreste del Cumandá, y explora sus hitos verticales en ambos sentidos. El quinto recorre varias zonas que se topan con el primer recorrido, al noroeste del
Cumandá, pero, en lugar de regresar, avanza hacia el norte, a través de la lluvia. El sexto recorrido se aleja significativamente hacia el norte de Cumandá y abarca un terreno sorpresivamente menos irregular que el resto de rutas.

Este registro se materializa en un insumo vital para este artículo, un recurso que figura en lo que Sarah Pink (2006) denomina hipermedia, concepto que surge de las narrativas multimedia de la era digital. En este caso, la edición y el procesamiento del video se combinan con la reconstrucción geográfica de los recorridos a través de la aplicación cartográfica de Google para elaborar un relato que conjuga narrativas de varios medios digitales.

Este procesos se concreta en un mapa realizado mediante Google Maps, en el cual se detallan las seis rutas que componen el registro y se marcan los puntos de mayor densidad motriz, a la vez que se incluye una secuencia de video que corresponde al respectivo punto. Este material permite contrastar los puntos recorridos desde la lógica del espacio ocupado, en este caso, geolocalizado en el mapa, frente al que se produce en la práctica mediante el movimiento, de cuya experiencia queda cierto registro vivencial en el video.

Este registro, desde los diversos planos y movimientos de cámara, presenta rastros de los afectos que subyacen en esos movimientos, localizables en los gestos o expresiones particulares de la acción motriz, en esa comunicación o expresividad que se exterioriza desde el cuerpo de los participantes al movilizarse, "que se escapa a la representación discursiva" (Imilan Ojeda et al., 2015) y se acerca más a la corporeidad (Lindón, 2017), esa cualidad del sujeto cuerpo de expresar algo al momento mismo de moverse. 
De este modo, la experiencia del investigador se referencia con los elementos que revelan estos recursos investigativos multimedia respecto al espacio como representación, así como respecto a la experiencia que tienen los distintos participantes. A esto se suma un tercer vértice de triangulación, que corresponde a la perspectiva de esos participantes.

Esta perspectiva se recoge mediante una serie de entrevistas realizadas en junio de 2018 con varios de los participantes más recurrentes en el proceso de campo. En primer lugar, una entrevista de campo realizada a seis de los asistentes en un posterior séptimo recorrido nocturno, en donde los participantes hablan de los afectos y las dificultades que inciden en su práctica, tanto en ese recorrido concreto como en los anteriormente realizados.

En segundo lugar, una entrevista más amplia y con más participantes realizada como videoprovocación, técnica de investigación cuyo sentido y utilidad radica en su capacidad de generar criterios e “invocar la memoria más allá de comentarios contextuales" (Tapias Hernández, 2012, p. 68), desde una mirada retrospectiva sobre lo que se hizo en el proceso.

Esta entrevista fue realizada con un importante número de miembros del colectivo que participaron activa y regularmente en el desarrollo de la investigación. Los asistentes visualizaron un montaje preliminar de las rutas recopiladas en video y luego compartieron, algunos como respuesta a las preguntas, otros más espontáneamente, sus criterios, conceptos e interpretaciones tanto del video como de las ideas subyacentes en la práctica del grupo.

De este modo, todos los recursos investigativos dibujan vértices de triangulación que permiten comparar, contrastar, profundizar y expandir los diversos hallazgos y los descubrimientos principales que arroja el proceso investigativo. Los más importantes se detallan en la sección siguiente.

\section{Resultados, los}

\section{microescenarios territoriales del}

\section{trazador}

El proceso de aprendizaje en Étre Fort estuvo siempre impregnado de una idea clave: no se trata de aprender técnicas especiales para moverse, sino de recuperar las capacidades motrices del cuerpo, desde las más básicas hasta los movimientos grandes y vistosos. Si bien no todos tienen las mismas capacidades, cualquier persona es susceptible de explorar sus distintas habilidades motrices desde el propio cuerpo, y esa experiencia propia se transforma en un conocimiento respetuoso de los ritmos y los límites individuales.

Bajo esa propuesta, otro de los elementos fundamentales en este aprendizaje es el de la exploración. En este grupo, el perfeccionamiento de la técnica o técnicas específicas de la disciplina queda relegado a un segundo plano respecto a la exploración de cada participante de sus propias habilidades.

Si bien el parkour tiene sus técnicas específicas, aplicadas en los diversos movimientos que utiliza, el sentido de su aprendizaje no radica en habituar estas técnicas hasta su aplicación instintiva o automática, sino en desarrollar conciencia de lo que pasa en el cuerpo durante cada movimiento, de modo que esa técnica se pueda aplicar a distintas medidas, escenarios y complejidades espaciales de diversa índole. 
No consiste en mejorar la ejecución del movimiento hacia una maniobra cada vez más impecable, como sucede, por ejemplo, en la gimnasia olímpica, o incluso en ciertas ramas del parkour que apuestan por su espectacularidad. Se trata, más bien, de perfeccionar la capacidad de acoplar los diversos movimientos o habilidades que se conocen a cualquier escenario espacial para poder moverse por él con soltura fluida.

En esa adaptabilidad a múltiples escenarios aparecen los primeros fenómenos afectivos importantes para la investigación. Por ejemplo, para muchos de los nuevos resultaba difícil cambiar el brazo o la pierna de apoyo de izquierda a derecha, incluso en los movimientos más simples. Una distancia previamente sorteada con un salto se volvía más difícil cuando se le agregaba un pequeño obstáculo en medio.

Todas estas situaciones revelaron paulatinamente uno de los escenarios afectivos más recurrentes e importantes en esta práctica: el miedo, asociado a otros similares como la duda y la inseguridad. Al examinar este miedo, resultó particularmente interesante examinar de dónde procedía y cómo se manifestaba. En ocasiones, provenía de una experiencia previa poco o nada habitual, como cambiar la mano o el pie de apoyo usual. En otras, procedía de alguna complejidad propia del espacio, como el riesgo de impactar sobre el obstáculo en medio del salto.

La observación participante reveló que estos afectos generaban consecuencias en las acciones motrices de los participantes. Muchas veces el miedo disuadía a los participantes de intentar una maniobra, incluso luego de meditarlo un buen rato, tratando de convencerse de que lo pueden hacer. En otros casos, algunos participantes se lanzaban hacia un salto para después arrepentirse y recoger los pies en el último momento.

Los talleres buscan explorar esos límites que dibuja el miedo y pulir las habilidades motrices para poder dominarlos, en un proceso que acumula una memoria muscular. No obstante, esta experiencia que se acumula no representa una certeza, sino una referencia de las capacidades, que se pone a prueba en el espacio propiamente urbano a través de los recorridos nocturnos.

En este escenario, la ciudad se torna, como dice Thrift (2008, p. 171), en "una vorágine de afectos". Las dificultades propias del espacio crecen exponencialmente, tanto en tamaño y dimensión como en complejidad. La influencia de los afectos que provoca este espacio recorrido se acentúa mucho más claramente en los participantes. Muchos puntos ralentizan notoriamente el ritmo del recorrido, por la duda y dificultad que suscitan, y varios otros llegan a disuadir a varios participantes de realizar ciertos movimientos.

Con esta observación surge uno de los conceptos centrales de esta investigación: la barrera afectiva, un obstáculo que surge de las percepciones que adquiere el trazador al experimentar el espacio en que se moviliza y que dificulta o incluso disuade al practicante de realizar movimientos que, muchas veces, le son teóricamente posibles por su capacidad o son similares a los movimientos realizados previamente en el contexto del taller.

En varios puntos de los recorridos se pueden apreciar estas barreras. Una potencial caída vertical en medio impide a muchos realizar un salto cuya distancia parecía dominada en el taller. Una superficie llena de salientes y agarres propicios para trepar se vuelve más difícil conforme más alto se ascien- 
de. Mientras la altura relativamente segura queda atrás, las percepciones del participante merman su seguridad en el propio movimiento y ralentizan, si no paralizan, su desplazamiento.

Frente a esto, en la práctica del parkour, el trazador desarrolla sus habilidades motrices hasta lograr los movimientos que le permiten recorrer ese espacio. Progresivamente supera estas barreras afectivas a través del cuerpo y genera un devenir o mutación, que aquí viene definido como ganancia afectiva, la cual se alimenta progresivamente de estos logros hasta transformar la identidad del habitante en uno capaz de conquistar las barreras afectivas.

En la ganancia afectiva se hallan frecuentemente afectos de tinte positivo, que aumentan la capacidad de acción, como la confianza, la satisfacción ante el logro del movimiento y, en muchas ocasiones, el disfrute que se vive en el hacer colectivo del grupo, como señalan los participantes en la videoprovocación. Sin embargo, esto no significa disipar el miedo, ya que este, como señala Camilo, líder de la agrupación, en realidad nunca desaparece. Aunque se lleven años practicando, lo único se hace es aprender a controlarlo.

En otras palabras, la ganancia afectiva también implica aprender a lidiar con el miedo, a sentirlo de tal forma y a tal nivel que el trazador es capaz de transformar su connotación típicamente negativa y reductora de la capacidad de acción hasta volverlo un playmate (Saville, 2008). A través de la ganancia afectiva, el practicante genera conquistas motrices sobre el territorio y supera en el trayecto no solo los obstáculos materiales o las restricciones sociales, sino, además, las barreras afectivas que se levantan sobre el espacio a raíz del miedo.

Estas transformaciones tienen su implicación en el practicante no solo como aficionado del parkour, sino como habitante de la urbe. Se modifica su capacidad para movilizarse hacia más espacios y más amplias dimensiones, es decir, para habitar corporal y emocionalmente un territorio urbano más extenso y diverso en complejidades. Al mismo tiempo, estas transformaciones se materializan sobre el territorio, principalmente sobre el tinte emocional que se dibuja, por medio del movimiento, en el espacio atravesado.

Este tinte emocional que deja el trazador sobre el espacio al moverse por él se relaciona con el concepto de microescenarios territoriales del sujeto sentimiento (Lindón, 2009). Este planteamiento esboza algunos escenarios en donde el sujeto sentimiento se devela en la práctica espacial que desarrollar el habitante. De entre los escenarios que menciona Lindón en el planteamiento de este concepto, el que mejor se acomoda al análisis del parkour es el de conquista, es decir, el que brota de “la apropiación del lugar" (Lindón, 2009, p. 15).

En este escenario particular, la localización del sujeto cuerpo en ese espacio representa en sí misma una conquista. No busca tanto discutir la discursividad preestablecida en el espacio ni desarrollar en él una práctica tecnificada previamente o dotarlo de una nueva estética o discurso, sino llegar o ubicarse en ese punto del espacio "precisamente porque la localización constituye en sí misma un logro" (Lindón, 2009, p. 15).

La práctica de Étre Fort lleva de frente hacia varios ejemplos de este escenario territorial. El llegar a puntos abrumadoramente altos o tan intrincados que parecen imposibles para un desplazamiento plenamente corporal implica una conquista del espacio, no solo motriz, sino también afectiva, de modo tal que a su paso tiñen el terreno de esta afectividad que transforma ese terreno en territorio 
ganado, susceptible de tránsito, no pese a, sino a través de ese miedo que estos espacios provocan.

Este territorio conquistado puede entonces llamarse también territorio ganado, al asociarlo a la ganancia afectiva. Sin embargo, al ser un espacio transitado, que se construye al practicarse, no es precisamente un territorio permanente, sino que se volatiliza en el tiempo y se modifica permanentemente. Así mismo, las habilidades motrices del trazador, al ser un sujeto fenomenológico siempre en construcción, están bajo constante actualización y crecen en varias direcciones, por lo que este territorio ganado se produce y reproduce permanentemente a través del accionar motriz del practicante.

Aunque este territorio no se fija o emplaza en el espacio, los trazadores dejan sus vestigios al habitar corporal y emocionalmente este territorio urbano. Estos vestigios son rastreables y observables a través de mecanismos como el video y el mapeo de los puntos de alta densidad motriz, de cuyo análisis derivan elementos para evidenciar esa transformación territorial y localizarla en las relaciones entre cuerpos que sostienen trazadores y espacio.

\subsection{El esfuerzo, la primera barrera}

Uno de los elementos centrales en la enseñanza, entre los mismos principios que guían la práctica particular de Étre Fort, es lo que Camilo denomina la cultura del esfuerzo. Esa determinación que implica saber, y sobre todo reconocer, que el esfuerzo es el único camino para ver resultados, para cualquier practicante. Esto plantea una primera barrera sumamente clara, en la cual varios miembros son enfáticos al repetir que el primer gran obstáculo a superar es el confort. Salir de la zona de confort es la única vía para superar las limitaciones y alcanzar los objetivos que te propones.
La primera de todas las ganancias afectivas es la que surge de romper esa posición inerte. Radica en esa conciencia que adquiere el practicante al disponerse a romper sus límites y alcanzar paulatinamente los resultados que persigue. Esa capacidad de convencerse a sí mismo de que se es capaz de afrontar los esfuerzos requeridos para completar los desafíos, aun dentro de las propias limitaciones, pero afuera de la zona de confort.

Bajo esta perspectiva, el primer escenario territorial es el que se describe por los límites y los contornos que dibuja la capacidad de esfuerzo que tiene el practicante para movilizarse desde su cuerpo. No tanto desde una distancia calculada como el máximo teórico de sus capacidades corporales, sino en relación con la dimensión o la cantidad de movimiento que esté dispuesto a esforzarse por recorrer.

En ese sentido, la barrera afectiva tiende a endurecerse no solo entre mayor es la distancia, sino principalmente en tanto mayor es el esfuerzo que requiere su recorrido. Sobre esas limitaciones, el practicante de parkour genera ciertas ganancias a través de su constancia y su crecimiento en la práctica, que le permiten reconocer sus propios logros y notar cómo se expanden los límites de sus capacidades. Estos se describen en la videoprovocación como hitos y medallas que cada practicante va colgando en el cúmulo de sus experiencias, para ponerlas a prueba en cada nuevo desafío.

No son, por tanto, escenarios territoriales que se puedan medir o escalar con exactitud, pero al examinar los datos generales que arroja cada recorrido aparecen algunos elementos que permiten caracterizar este escenario. Entre estos datos, se puede ver la longitud de los tramos y contrastarla con la cantidad de movimiento que se registra en cada uno 
para relacionar esa cantidad de movimiento con el esfuerzo que requieren.

En este sentido, las rutas 3 y 4 (Figura 2), por ejemplo, abarcan al rededor de seis kilómetros en ambos casos y recorren una trayectoria muy similar. Sin embargo, en todo ese trayecto son fundamen-

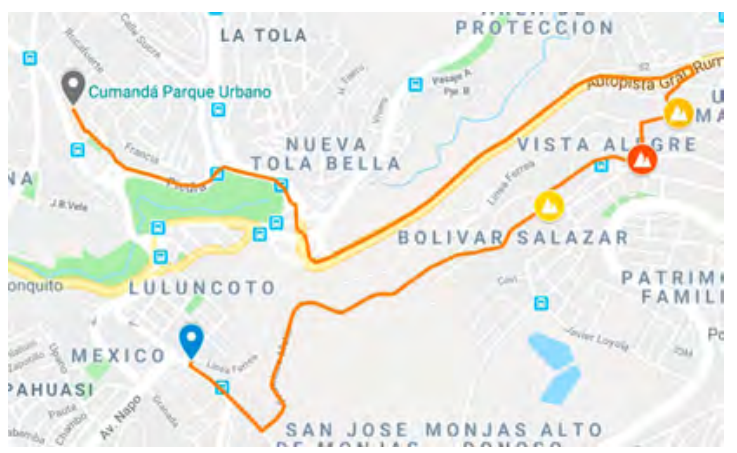

talmente los tres puntos que desprenden la mayor densidad motriz, tanto en sentido ascendente como descendente. Si los comparamos con los tramos más lineales y planos del trayecto vemos que su longitud es bastante corta, pero el movimiento que requieren es mucho más variado y complejo, por lo que demandan mucho más esfuerzo.

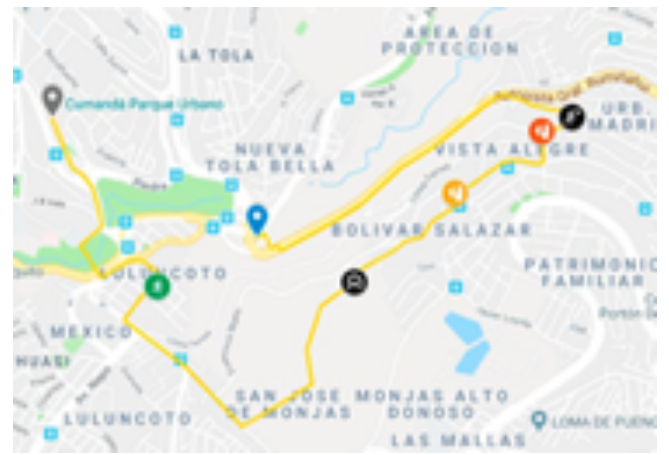

FIGURA 2.

Rutas 3 y 4, de izquierda a derecha, con sus puntos desplegados. Fuente: Vásconez Vaca (2018). Cartografía 1. Territorio emocional ganado.

Así, la ruta 6 (Figura 3) marca un recorrido aproximado muy cercano a los siete kilómetros y no es tan prolífica en puntos marcados como la ruta 1 (Figura 3), que tiene cerca de medio kilómetro menos, o como la ruta 5 (Figura 3), que tiene un kilómetro menos. Estas dos últimas atraviesan varios sectores en común, localizados al noroeste del Parque Cumandá. En estas áreas, el mobiliario y la disposición espacial se complejizan y presentan centros de movimiento más amplios y diversos que los que presenta la ruta 6 , la cual recorre un área visiblemente menos irregular. Estos espacios presentes en las rutas 1 y 6 requieren mayor esfuerzo en tanto que, sin implicar mayor distancia, generan más movimiento.
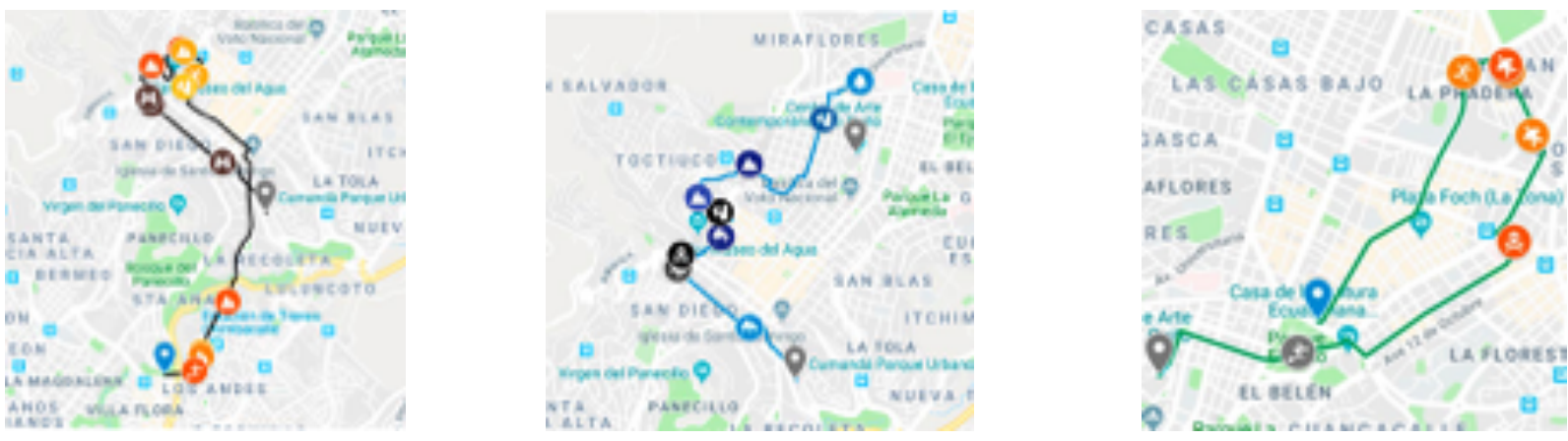

FIGURA 3.

De izquierda a derecha, rutas 1,5 y 6 , con sus puntos desplegados.

Fuente: Cartografía 1. Territorio emocional ganado. 
De estas comparaciones se puede extraer la incidencia que tiene la irregularidad vertical del terreno quiteño en la producción de su espacio y las formas de movilidad que se generan sobre este. Casi todos los puntos marcados denotan un trayecto ascendente o descendente, de modo que la movilidad se desarrolla en las condiciones que dictan estas características del terreno.

En estos espacios se genera una especie particular de lugares transientes en estructuras como puentes peatonales o escalinatas, espacios con alta movilidad que tienen esta peculiaridad de permitir el trayecto solamente al cuerpo, y que generan un pasaje directo entre dos puntos del espacio a diferente altura. En ellos se condensa la distancia y se traza una vía directa sobre esta característica del terreno, pero se permite el movimiento solamente al cuerpo, lo cual implica un esfuerzo inherente que brota de este.

A ese respecto, el esfuerzo que se pretende evitar desde el confort, o que se considera como tiempo muerto, se convierte aquí en una ganancia que permite expandir la capacidad del habitante para alcanzar un territorio cada vez más extenso e intrincado por medio de su movilidad afectiva. Permite conquistar no solo un terreno más amplio en cuanto a su extensión, sino en cuanto a formas y libretos de movilidad, en donde se pueden combinar diversos esfuerzos en determinados puntos para obtener mayor despliegue y conquistar más territorio.

\subsection{Barreras afectivas por alto riesgo}

Esta categoría grafica claramente la noción de conquista del espacio desde la mera presencia en este. En este tipo de escenarios, el movimiento puede Vol. 24 N. ${ }^{\circ} 2$ no ser esencialmente difícil, pero el espacio que se atraviesa con ese movimiento dibuja un profundo riesgo para el practicante. Por ejemplo, equilibrar sobre una superficie a gran altura, saltar entre dos puntos con una larga caída en vertical de por medio o descender desde un punto alto por una pared sin muchas opciones de agarre. Todas estas situaciones implican habilidades motrices y formas de desplazamiento distintas, pero tienen en común una configuración espacial que las dificulta y un riesgo sumamente peligroso en caso de fallar en la ejecución del movimiento.

En este escenario, la ganancia afectiva viene de la cenestesia o percepción propia que se adquiere, la capacidad de asimilar en esa memoria muscular una percepción mucho más amplia del propio cuerpo y todas las partes involucradas en su movimiento, cada una en su función. De esta capacidad surge la habilidad de aplicar los conocimientos motrices aun a pesar de los fuertes afectos que genera el espacio al presentar una dificultad tan peligrosa.

Esto permite conquistar el territorio de más complejo alcance y asequibilidad para el sujeto cuerpo. Llegar a puntos donde, para otros, el cuerpo sería un medio motriz insuficiente, y tener la capacidad de trasladarse por allí, aunque no sea lo cotidiano. Es decir, si bien no será un punto de traslados diarios o recurrentes, si la circunstancia o el deseo del habitante lo requieren, el llegar a este punto por medio del cuerpo deja de ser un propósito utópico, la superficie deja de ser infranqueable y el habitante, aun intimidado, es capaz de controlar su percepción y usar su miedo para volver posible el traslado por ese punto del espacio.

Un claro ejemplo de esto lo vemos en el punto denominado túnel de San Roque, en la ruta 5 (Figura 
4) de la cartografía que complementa este artículo. Aquí, si bien la superficie es plana y no resulta difícil equilibrarse sobre ella, el desafío está en dominar los afectos que produce el tener una larga y posiblemente fatal caída vertical hacia la izquierda, por donde los vehículos fluyen recurrentemente a la salida del túnel.

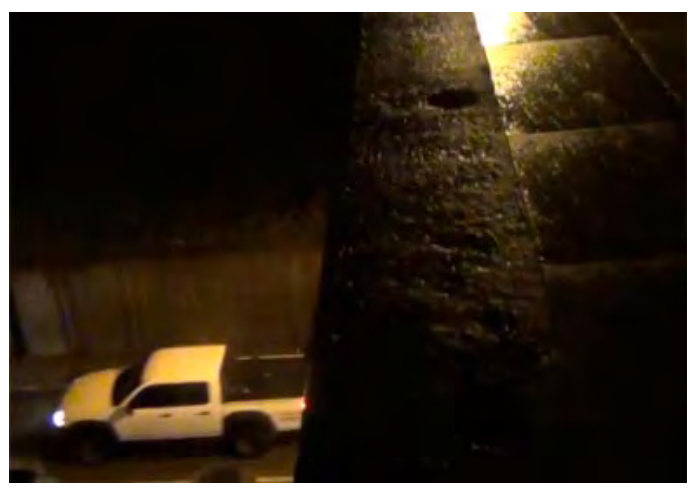

\section{FIGURA 4}

Plano subjetivo del trayecto por la cima del túnel de San Roque.

Fuente: Cartografía 1. Territorio emocional ganado.

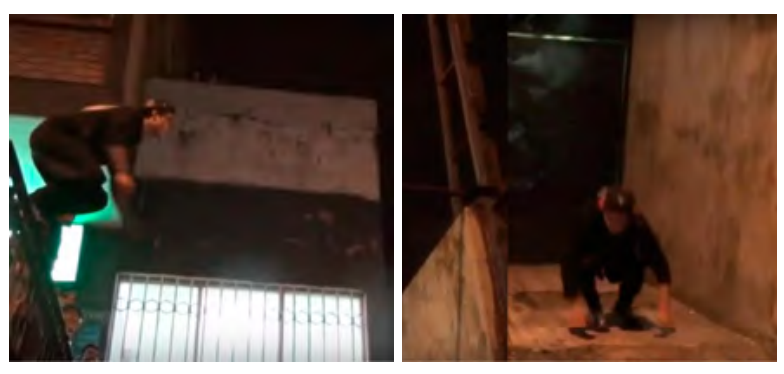

FIGURA 5.

El salto de Jeff, distancia lateral y descenso vertical. Fuente: Cartografía 1. Territorio emocional ganado.

Otro de ellos corresponde al punto Colón y José Tamayo (Vásconez Vaca, 2018), en la ruta 6, en donde Jeff (Figura 5), uno de los más osados miembros de Étre Fort, realiza un impresionante salto que luego nadie más intenta, ni siquiera Camilo. En este punto confluyen varios factores de riesgo, sobre todo la larga distancia entre el punto de salida y de llegada del salto, así como la considerable altura a la que se desarrolla el movimiento, que si bien podría no ser potencialmente fatal, como en el caso anterior, sí representa un riesgo, cuando menos, de lesiones peligrosas.

Un ejemplo más a destacar es el punto calle Isidro (Figura 6) de la ruta 1, un descenso a través de una alta pared lisa dividida en paneles cuadrados. Aquí no solo la altura representa un claro riesgo, sino que, además, la forma de la pared brinda pocos puntos de apoyo, lo que dificulta controlar el desplazamiento en descenso, el cual, además, se da de espaldas al punto de destino, lo que dibuja un riesgo de caer de espaldas varios metros en vertical: un escenario potencialmente muy peligroso.

\subsection{Barreras afectivas por la agresividad del espacio}

En este escenario, la barrera afectiva procede de varios espacios públicos, mobiliario e infraestructuras que presentan condiciones de precariedad y deterioro perceptibles en más de un sentido. Olores desagradables, formas agresivas y texturas desgastadas que generan un pasaje que, paradójicamente, está hecho para movilizarse, pero repele casi todo flujo por allí pretendido.

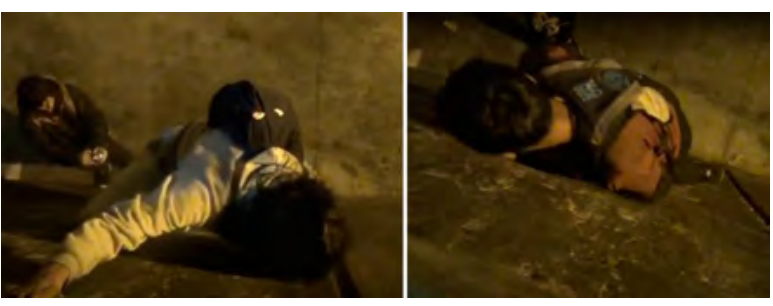

FIGURA 6.

Practicantes descendiendo con dificultad por el muro de la calle Isidro.

Fuente: Cartografía 1. Territorio emocional ganado. 
Estos espacios generan una fuerte barrera afectiva por lo desagradable de las experiencias sensoriales que allí se tienen. El más claro ejemplo de estos escenarios fue hallado en el punto Pedro Fermín Cevallos y Chile, en la ruta 2 (Vásconez Vaca, 2018), en donde inmediatamente resalta la presencia de una rata muerta en las inmediaciones del muro a escalar, cuyo olor despunta entre los varios factores de precariedad que dificultan el trayecto.

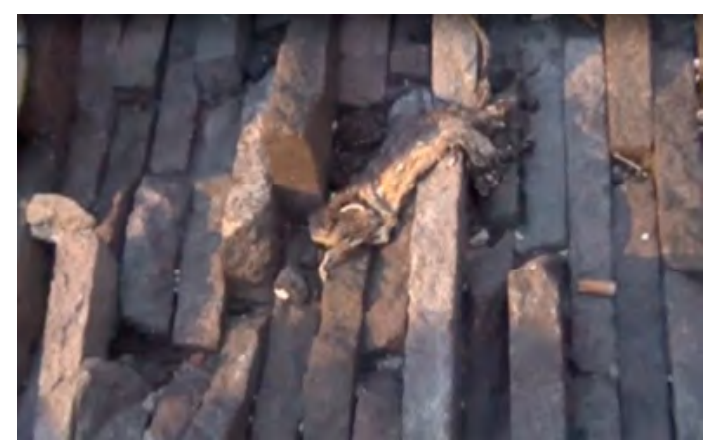

FIGURA 7.

Acercamiento al cuerpo de la rata muerta hallada en la ruta 2.

Fuente: Cartografía 1. Territorio emocional ganado.

Otro de los espacios a destacar en este sentido es un punto que aparece en tres rutas distintas, denominado Bulevar 24 de Mayo, en donde los niveles de precariedad son bastante parecidos. Este puente fue escenario de una curiosa historia que relató en la videoprovocación Edwin, miembro destacado del colectivo.

Según su relato, en una ocasión fueron increpados por uno de los enajenados sociales que ocupan frecuentemente este puente como espacio de residencia. Tal fue el reclamo que el sujeto amenazó con llamar a la policía si los jóvenes practicantes no se iban del sitio, al cual este hombre consideraba como su territorio fijo, que debía proteger de la amenaza externa.
Esto da cuenta del alcance que puede tener la precariedad de estos espacios. Muchos de ellos caen en una espiral de deterioro en la cual se vuelven indeseables o repulsivos para el grueso de los habitantes, y se los excluye de las prácticas de movilidad. Se deja de usar ese espacio debido a su deterioro, y, consecuentemente, se le entrega al deterioro: un callejón sin salida aparente.

Ante esto, el quehacer de Étre Fort genera una forma interesante de ganancia afectiva, que Camilo describe como un reciclaje de los espacios. Camilo considera que, al trazar por estos espacios, los miembros del grupo los reutilizan de una forma nueva respecto a su uso cotidiano, pues, lejos de su diseño original, se usan a diario más como baño o basurero, y les devuelven su sentido de movimiento al subvertir el libreto motriz que allí se dibuja.

En otras palabras, los trazadores toma elementos del espacio hechos para regular la forma correcta de flujo, como los muros provistos de púas o las barandas de los puentes, y exploran otras formas de motricidad allí. Esto les permite conquistar el espacio y recuperarlo para otros usos distintos a los que se aplican allí regularmente, como baño o botadero. Al practicar de esta forma los espacios, dice Camilo, queda en materia y en espíritu la huella que se deja al hacer algo en un espacio que nunca fue diseñado para eso, o, mejor dicho, que fue diseñado para ello, pero no de la forma que los practicantes aplican.

Esto representa una forma de reivindicación del espacio que en cierto modo trasciende esas limitaciones discursivas y va más allá del reclamo, la identificación, la caracterización o la definición de estos espacios como tóxicos o altamente agresivos. Los recupera de forma práctica dentro del circuito de interacciones sociales con el espacio. Reivindica el espacio, no en tanto lo resignifica respecto a 
su connotación social imperante, sino mucho más en tanto lo vuelve a practicar y vuelve a generar espacialidad por medio de prácticas motrices que se involucran con estos espacios.

\subsection{Barreras afectivas que surgen del propio cuerpo}

El sujeto cuerpo, como ser fenomenológico, se mueve entre la percepción, la intuición y la conciencia; está en permanente construcción, abierto e ilimitado (Lindón, 2017). Por lo tanto, la realidad corporal del trazador está, así como sus habilidades, en permanente transformación. Es así que su capacidad de acción motriz en el espacio no solo depende del nivel de sus habilidades, sino también de las condiciones que presenta el cuerpo al momento de realizar cada desplazamiento, las cuales se ven modificadas según factores como el desgaste y el esfuerzo previos, elementos somáticos que se tornan en afectos y pasan a formar una barrera.

No es lo mismo intentar una maniobra difícil al principio del recorrido que cuando el cansancio ha pasado factura. Lo propio sucede cuando uno se recupera de una lesión o cuando en el trayecto, previamente, ha sufrido un golpe o cortada. Todos estos elementos modifican las condiciones en las que uno se halla físicamente en cada momento del recorrido. Muchas veces, la barrera afectiva que impide un determinado movimiento, en principio posible, o al menos realizado en ese punto previamente, es el desgaste en sus diversas formas.

Ante ello, la conquista emocional proviene de ese saber fundamental que reemplaza el dominio de la técnica por la exploración. No se escoge entre hacer o no un movimiento, sino entre un movimiento $\mathrm{u}$ otro. Saber comprender las condiciones del propio cuerpo y adaptar el movimiento a esas capa- cidades también es una forma de ganancia sobre el territorio, pues nos hace comprender que no es el movimiento en sí el que permite esa conquista, sino la capacidad de moverse a través de ese espacio desde las capacidades del propio ser.

En ese sentido, el caer deriva también en una habilidad, en tanto el movimiento no se acaba. Entre los episodios recogidos por el documental, se pueden observar algunas caídas en donde parte del ingrediente es saber responder ante el suceso. La más destacada, es la caída que sufre Kat, practicante de Étre Fort, en el punto Manuel Quiroga y Mideros de la ruta 5 (Vásconez Vaca, 2018). En este trayecto, ella logró, como dicen los miembros del grupo, salvar la caída, es decir, generar una reacción para evitar un impacto directo o un daño significativo.

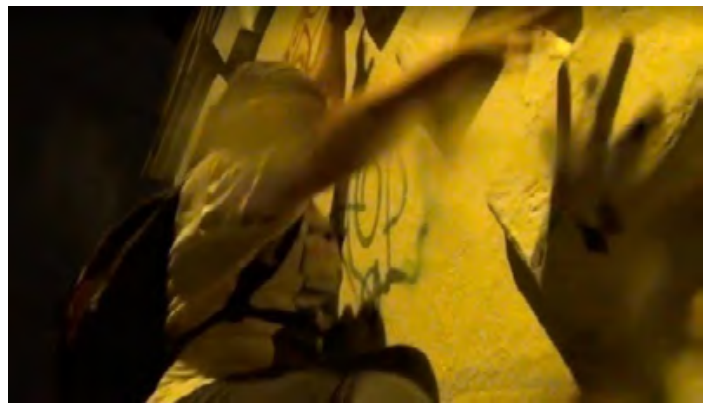

FIGURA 8.

Momento previo a la caída de Kat, vista preliminar. Fuente: Cartografía 1. Territorio emocional ganado.

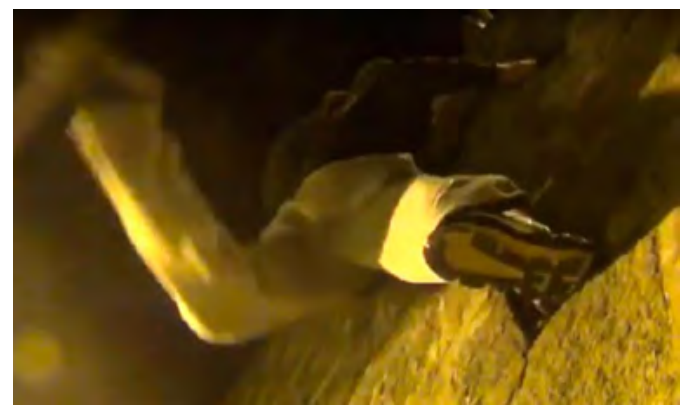

FIGURA 9.

Momento en que este trazador pierde la caída justo antes de caer sobre el camarógrafo.

Fuente: Cartografía 1. Territorio emocional ganado. 
Otro de los casos ocurre en el punto Parque Matovelle de la ruta 2 , en donde, al subir un muro alto y difícil, uno de los asistentes pierde el agarre y se desprende del muro para caer directo y de lleno sobre el camarógrafo (Figura 9). Episodio que endurece, pero no finaliza el recorrido nocturno para ninguno de los dos, pues la secuencia cierra con una toma, desde la cima del muro, en la que este mismo participante se repone y supera finalmente este ascenso.

De esta situación también surge una ganancia afectiva, pues lo que arroja la experiencia no radica tanto en el movimiento incompleto, que se podría considerar, en otra óptica, como un fracaso, sino en la capacidad de reacción que se halla frente a la eventualidad de la caída. El caer no es tanto un fallo como otra forma de moverse en el espacio, de redibujar el miedo, en principio paralizante, en un movimiento que finalmente permite atravesar ese espacio, conquistarlo desde la mera presencia del cuerpo en ese tramo.

El sentido final no es hacerlo para que alguien lo vea ni demostrar que se puede hacer el movimiento, sino llegar a ese lugar o desplazarse por ese tramo del espacio. Es por ello que, ante una barrera afectiva como el cansancio o el daño de un golpe previo, la conquista emocional deriva en comprender el propio ritmo y condiciones, lo que lleva finalmente, con otros recursos tal vez menos espectaculares, pero efectivos, finalmente, a conquistar ese espacio o trayecto.

\section{Conclusiones}

Una de las primeras conclusiones en aparecer es que estas barreras afectivas no aparecen de forma única y exacta en cada espacio, no se dan una cada vez, sino varias en simultáneo. El espacio se experimenta de forma polidimensional y los varios aspectos que se perciben pueden generar diversas barreras afectivas en un mismo trayecto o en una determinada producción motriz del respectivo espacio.

En una mirada más profunda, se puede concluir que la conquista de esas barreras afectivas abre las puertas para una movilidad más participativa en la que el trazador, como habitante de la ciudad, adquiere mayor capacidad de acción política en el espacio urbano. Esa capacidad de acción surge de un empoderamiento emocional del habitante, quien al transformar afectivamente su identidad a través de la práctica se siente con mayor capacidad de movilizarse por la ciudad, de diversas formas y con varios recursos, trazando sus propios libretos de movilidad, construyendo sus propias prácticas de habitar motriz.

Ese empoderamiento emocional incentiva la capacidad de acción. En el trazador, esta capacidad se transforma en acción política por cuanto involucra esas habilidades para habitar la urbe, en la pugna no por significar, connotar o representar el espacio de determinada forma, sino por practicarlo y reproducirlo a través de la movilidad. Esta movilidad toma postura respecto a ciertas situaciones concretas. Rechaza el confort y opta por el cultivo y la valoración de los distintos esfuerzos que llevan al crecimiento. Pierde en comodidad, seguridad y eficiencia, para ganar en libertad, autodeterminación y capacidad de decisión al momento de practicar el espacio cotidiano, el que se vive día a día.

Entre los horizontes políticos que expande esta capacidad de acción, uno sumamente importante, que se abre a discusión, es el de la accesibilidad, la forma en que esta capacidad de acción pone al 
alcance del cuerpo espacios que de otra forma serían inaccesibles. La discusión por el acceso, desde la planificación territorial y la "geografía de la accesibilidad" (Gutiérrez, 2010), procura generar acceso desde la producción del espacio y busca mecanismos para satisfacer las necesidades de los habitantes de acceder a bienes y servicios, pero debería implicar generar acceso hacia el espacio urbano desde la propia capacidad del habitante.

Esta enseñanza de Étre Fort pone ese planteamiento en discusión, una discusión que se explora en la ciudad con cada recorrido. ¿Qué tanto lejos puede llevar al habitante esta exploración motriz respecto a las fronteras de accesibilidad impresas en la producción del espacio? La propuesta del colectivo invita a ver la movilidad y el movimiento como una cuestión social esencial, presente en todos los días de nuestra vida, que se puede explorar y mejorar no solo para practicar un deporte, sino para elaborar mejor el movimiento que día a día se vive en la ciudad. Se pueden encontrar soluciones a esos problemas de acceso o de movilidad también desde uno como habitante, desde la apropiación del espacio por medio de la acción motriz.
Esto no quiere decir que el trazador de Étre Fort puede prescindir del sistema de transporte urbano y movilizarse solo a base de parkour, pero sí implica que todo ese aprendizaje, experiencia y conquista emocional deben transcender ese escenario de la práctica recreativa y convertirse en parte de la experiencia cotidiana de la ciudad. En este sentido, como conclusión final, se puede señalar que existe un sentido crítico, o más precisamente, una marcada postura de compromiso político que subyace en la propuesta de este colectivo.

Esta visión no solo se aleja de cualquier noción de competencia, sino que apuesta por trascender el sentido deportivo de una práctica predominantemente atlética para convertirla, según el mismo Camilo, en una práctica comunitaria y una cuestión social. Una manera de convertir el movimiento corporal en una forma curiosa, pero genuina, de movilización social, rupturista y transgresora de los esquemas preconcebidos, que lejos de contentarse con el reconocimiento y la difusión altamente espectacular, se torna en una práctica de habitar. 


\section{Referencias}

Augé, M. (2001). Los no lugares. Espacios del anonimato. Una antropología de la sobremodernidad. Barcelona: Gedisa.

Banco Mundial. (2002). Ciudades en movimiento: revisión de la estrategia de transporte urbano del Banco Mundial. Washington: Banco Mundial.

De Certeau, M. (2007). La invención de lo cotidiano. México: Instituto Tecnológico y de Estudios Superiores de Occidente, Universidad Iberoamericana.

Delgado, M. (1999). El animal público. Barcelona: Anagrama.

Goffman, E. (1979). Relaciones en lo público: microestudios de orden público. Madrid: Alianza Editorial.

Gutiérrez, A. (2010). Movilidad, transporte y acceso: una renovación aplicada al ordenamiento territorial. Scripta Nova. Revista Electrónica de Geografía y Ciencias Sociales, 14(0). https://doi.org/10.1344/sn2010.14.1736

Imilan Ojeda, W., Jirón Martínez, P. e Iturra Muñoz, L. (2015). Más allá del barrio: habitar Santiago en la movilidad cotidiana. Recuperado de http://repositorio.uchile. cl/handle/2250/135498

Jirón, P. e Iturra, L. (2011). Momentos móviles. Los lugares móviles y la nueva construcción del espacio público. Arquitecturas del Sur, 29(39), 44-57.

Leyden Rotawisky, J. (2013). Parkour, cuerpos que trazan heterotopías urbanas. Revista Colombiana de Antropología, 49(2), 41-61.

Leyden Rotawisky, J. (2015). El arte del extravío: corporalidades y afectos en el parkour. Revista Corpografías 2(2), 194-211.

Lindón, A. (2009). La construcción socioespacial de la ciudad: el sujeto cuerpo y el sujeto sentimiento. Revista Latinoamericana de Estudios sobre Cuerpos, Emociones y Sociedad, 1(1), 6-20.

Lindón, A. (2017). La ciudad movimiento: cotidianidades, afectividades corporizadas y redes topológicas. Inmediaciones de la Comunicación, 12(1), 107-126.

MacDougall, D. (2006). The corporeal image. Film, etnography and the senses. New Jersey: Princeton University Press.

Pile, S. (2009). Emotions and affect in recent human geography. Transactions of the Institute of British Geographers, 35(1), 5-20. https://doi.org/10.1111/j.14755661.2009.00368.x.

Pink, S. (2006). The future of visual anthropology. Engaging the senses. Londres y Nueva York: Routledge.

Saville, S. J. (2008). Playing with fear: parkour and the mobility of emotion. Social \& Cultural Geography, 9(8), 891-914. https://doi.org/10.1080/14649360802441440

Scarnatto, M. y Díaz, J. M. (2010). De peatón a traceur en una diagonal. El Parkour en la ciudad de La Plata. Nuevas prácticas, patrimonios motrices y formas de socialidad. 
Presentado en IV Jornadas de Investigación en Educación Corporal, 7-9 de octubre, Buenos Aires, Argentina. Recuperado de http://www.memoria.fahce. unlp.edu.ar/library? $\mathrm{a}=\mathrm{d} \& \mathrm{c}=$ eventos $\& \mathrm{~d}=\mathrm{Jev} 904$

Schargorodsky, J. (2015). El Parkour en Avellaneda. Tensiones entre reproducción social, violencia simbólica y los Libres del Sur. Presentado en $11^{\circ}$ Congreso Argentino y 60 Latinoamericano de Educación Física y Ciencias, 28 de septiembre al 10 octubre, Ensenada, Argentina. Recuperado de http://www.memoria.fahce.unlp.edu.ar/ trab_eventos/ev.7344/ev.7344.pdf

Sennett, R. (1997). Carne y piedra. Madrid: Alianza Editorial.

Simmel, G. (2002). Las metrópolis y la vida espiritual. En Técnica y cultura: el debate alemán entre Bismarck y Weimar (pp. 55-68). Buenos Aires: Ediciones Infinito.

Tapias Hernández, C. A. (2012). La foto provocación como método: fragmentos de memorias a través de las imágenes. En Nuevas Antropologías Colombianas (pp. 6696). Colombia: Editorial Zenú.

Thrift, N. (2008). Non representational theory. Space, politics, affect. New York: Routledge.

Vásconez Vaca, J. (2018, noviembre). Cartografía 1. Territorio emocional ganado. Recuperado de https://www.google.com/maps/d/viewer?mid = 1Sg9MvcnlNe_ cRNkdflvwiAhdNXSxFsOF\&fbclid = IwAR1CPI_g9QgLjTInKIBbN98SYJ1YTA WRMIv4qMf82n00-JXQfnJ102eCzZs\&ll = -0.21636812061266533\%2C$78.5024929 \& z=13$ 